\title{
Endoscopic submucosal dissection of Barrett's neoplasia into a stenosis: circumferential tunneling strategy with clip-and-line traction
}

Endoscopic submucosal dissection (ESD) is now validated for Barrett's neoplasia in case of visible lesions $>15 \mathrm{~mm}[1,2]$, and tunneling dissection $[3,4]$ is particularly effective when associated with clip-andline traction [5]. Here we report the case of a 57-year-old man referred for a short circumferential stenosis with high grade dysplasia at $28 \mathrm{~cm}$ from the dental arch. The stricture was not passable with a standard gastroscope, and we used a transnasal scope to avoid deep invasion and to confirm the distal margin of the neoplastic lesion under the stricture.

After submucosal injection, we created a circumferential incision and trimmed the superior edge $2 \mathrm{~cm}$ above the stricture ( $\triangleright$ Fig. 1, $\triangleright$ Video 1). Circumferential dissection allowed us to create a circumferential flap where we fixed clip-and-line traction.

We then created several submucosal tunnels, expanding them on both sides and progressively extending the circumferential flap. Thanks to the tunnel and traction, we were able to find a thin submucosal layer under the fibrotic area, which allowed us to perform submucosal dissection through the stricture circumferentially. At $32 \mathrm{~cm}$ from the dental arch, we created an inferior incision from the tunnel. We finished the inferior circumferential incision and the submucosal dissection. Stenosis was visible on the extracted specimen ( $\boldsymbol{F i g . 2}$ ) but disappeared in the esophageal lumen. Pathology on the specimen showed adenocarcinoma in situ and significant thickening of the muscularis mucosae. This suggests that the circumferential stenosis was superficial and that resection is safe and feasible using clip-andline traction and the circumferential tunneling dissection technique with a progressive strategy from the upper to the lower edge of the stricture. Stricture did not recur at 3 months' follow up.
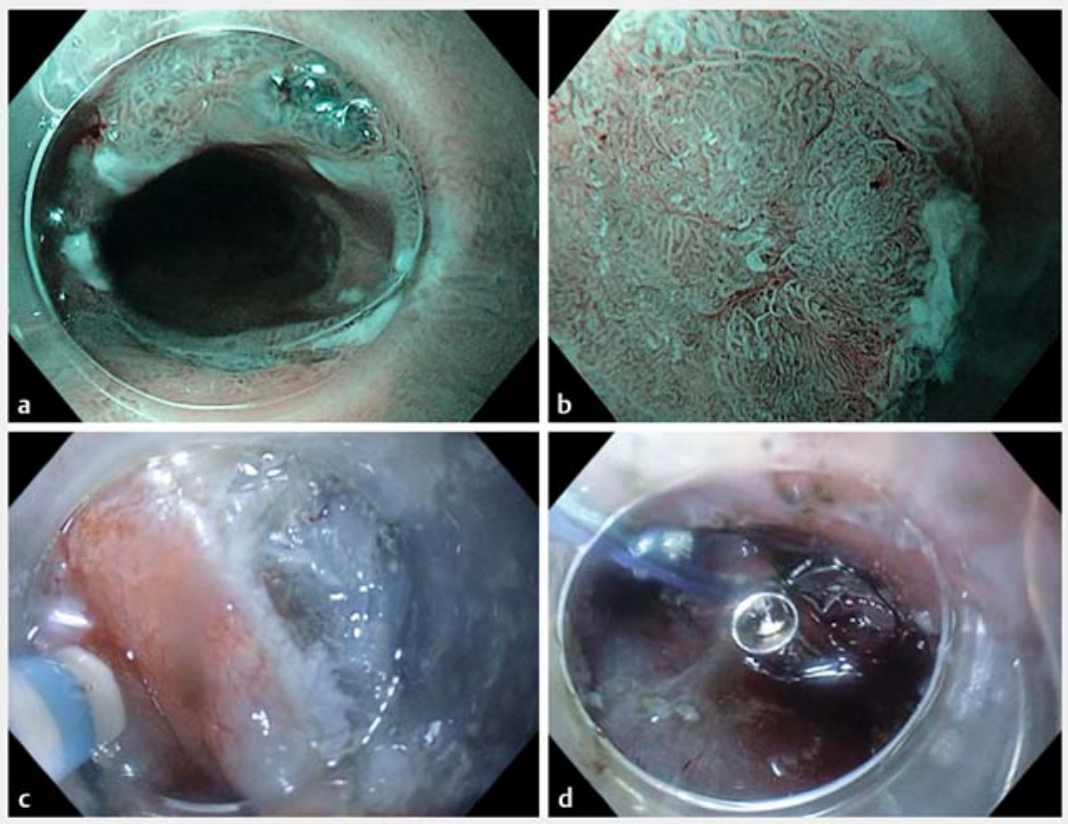

- Fig. 1 Aspect of the stenosis and start of the procedure. a Distant view of the stricture. b Close view of the irregular neoplastic component. c Proximal circumferential incision and trimming. $\mathbf{d}$ Circumferential flap traction with clip and line.

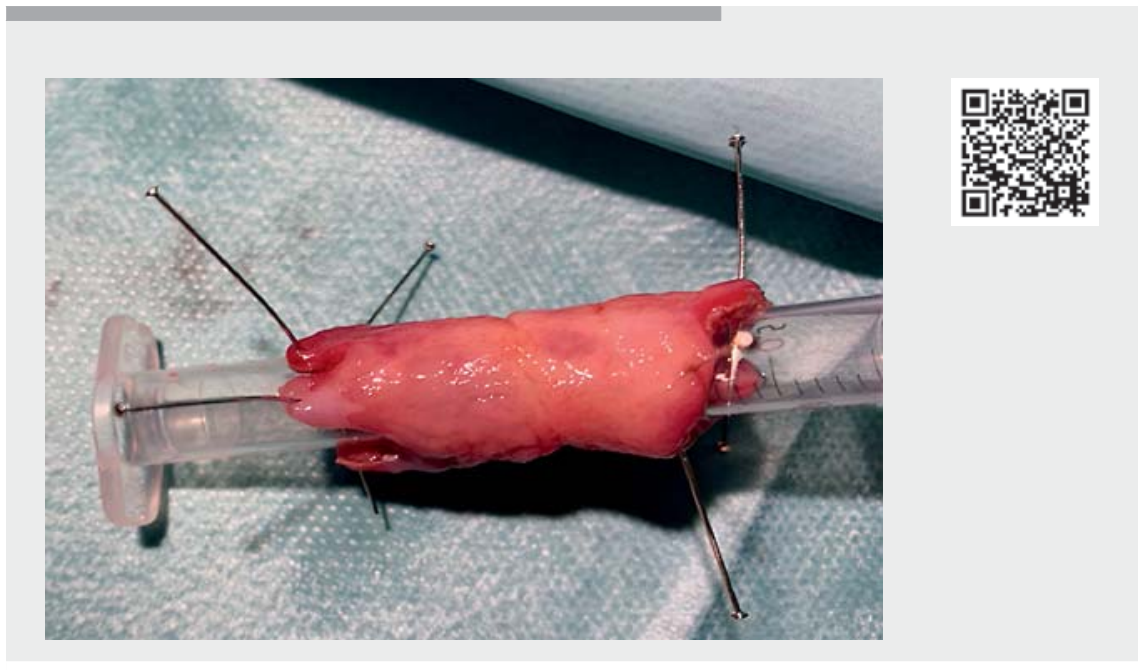

Video 1 Endoscopic submucosal dissection of Barrett's neoplasia into a stenosis: circumferential tunneling strategy with clip-and-line traction. 

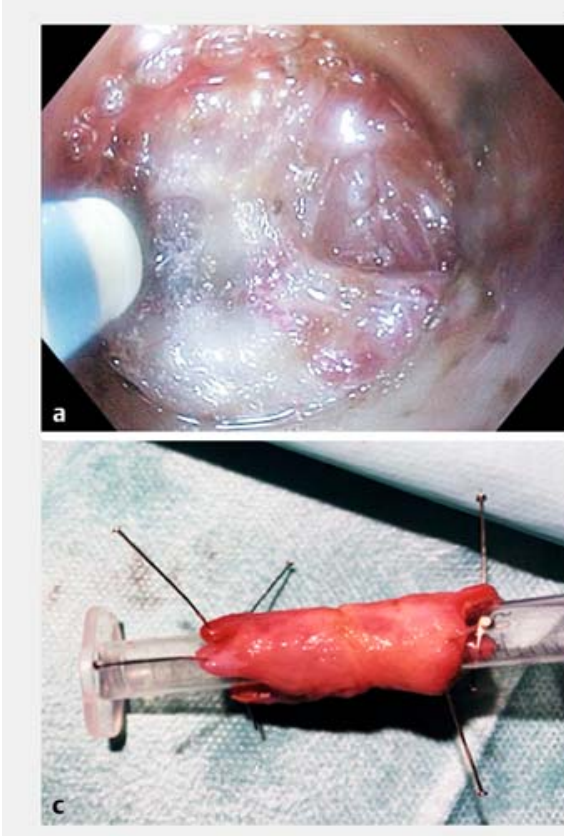

- Fig. 2 End of endoscopic submucosal dissection (ESD) procedure on the stricture. a Tunnel ESD in the stenosis area. b Tunnel exit under the stricture area. c Specimen with visible stricture. $\mathbf{d}$ Aspect of the esophagus after the procedure.

\section{Competing interests}

The authors declare that they have no conflict of interest.

The authors

Olivier Ragi, Florian Rostain, Borathchakra Oung, Thomas Lambin, Paul Bonniaud, Jérôme Rivory, Mathieu Pioche Department of Endoscopy and Gastroenterology, Pavillon L, Edouard Herriot Hospital, Lyon, France
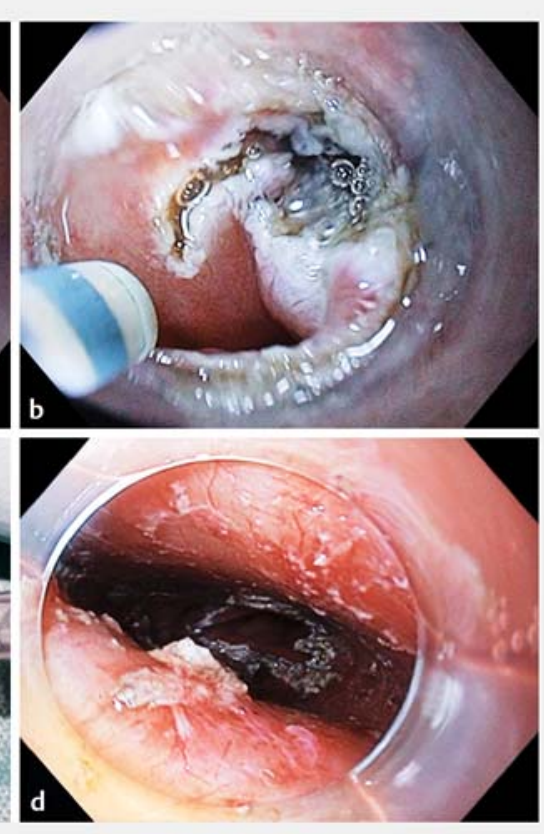

[2] Yang D, Zou F, Xiong S et al. Endoscopic submucosal dissection for early Barrett's neoplasia: a meta-analysis. Gastrointest Endosc 2018; 87: 1383-1393

[3] Linghu E, Feng X, Wang X et al. Endoscopic submucosal tunnel dissection for large esophageal neoplastic lesions. Endoscopy 2012; 45: 60-62

[4] Pioche M, Mais L, Guillaud O et al. Endoscopic submucosal tunnel dissection for large esophageal neoplastic lesions. Endoscopy 2013; 45: 1032-1034

[5] Jacques J, Legros R, Rivory J et al. The "tunnel + clip" strategy standardised and facilitates oesophageal ESD procedures: a prospective, consecutive bi-centric study. Surg Endosc 2017; 31: 4838-4847

\section{Bibliography}

Endoscopy 2021; 53: E394-E395

DOI 10.1055/a-1314-8953

ISSN 0013-726X

published online 17.12.2020

(c) 2020. Thieme. All rights reserved.

Georg Thieme Verlag KG, Rüdigerstraße 14, 70469 Stuttgart, Germany

\section{ENDOSCOPY E-VIDEOS}

https://eref.thieme.de/e-videos

\section{Mathieu Pioche, MD}

Endoscopy Unit, Digestive Disease Department, Pavillon L, Edouard Herriot Hospital, 69437 Lyon Cedex, France mathieu.pioche@chu-lyon.fr

\section{References}

[1] Weusten B, Bisschops R, Coron E et al. Endoscopic management of Barrett's esophagus: European Society of Gastrointestinal Endoscopy (ESGE) Position Statement. Endoscopy 2017; 49: 191-198 